\title{
Political Hedonism and the Wages of Prosperity
}

\author{
Stephen Eide
}

Two salient developments of modern history are the crisis of rationalism described by Mr. Bolotin and strong economic growth. Somehow, they must explain the divergent fortunes of political radicalism, which is up, and liberal education, which is down.

If we were all poorer, would the liberal arts have more of a fighting chance? From a classical perspective, prosperity creates the conditions for liberal education. Leisure requires prosperity, as does patronage. America has substantial cultural infrastructure thanks to, for example, the public library movement in the late nineteenth century and early twentieth century, and the Great Books movement in the mid-twentieth century. Even backlashes against prosperity can benefit the liberal arts. Many young Americans find their way to the life of the mind through seeking an escape from materialistic values.

For still more youths, though, that escape leads to political commitment. The 1962 "Port Huron Statement," a foundational text of modern American radicalism, opens by noting its authors' background of having been "bred in at least modest comfort." Last summer, tabloid newspapers ran many profiles of youths arrested for rioting. A preponderance seem to have been college-educated white kids. Since the 1960s, the benefits of prosperity have not been equally shared, as young radicals often point out. But it seems safe to assume that young radicals themselves disproportionately hail from families that have had a decent run.

Over the last forty years, the upper middle class has at least doubled, perhaps even tripled in size, depending on which metrics you use. There should have been ample enough new recruits for both the liberal arts and radical political movements. And yet, it's been a rout. Interest in radicalism keeps growing. The liberal arts look even weaker now than they did in 1987 when Allan Bloom's Closing of the American Mind declared them to be in a state of crisis.

Stephen Eide is a senior fellow at the Manhattan Institute and a contributing editor of City Journal; he is a graduate of St. John's College in Santa Fe, NM, where he studied under David Bolotin, and Boston College. 
I graduated from a liberal arts college in 2001. In my undergraduate days, politics was a hobby. Some of my peers were exercise nuts, some liked swing dancing or bluegrass, others followed the news. Since then, political commitment has become more central to young Americans' view of the good. You can't be just vaguely sympathetic to either the Democrats or Republicans, which is how it went back in the late 1990s. Anyone who keeps politics at arm's length risks being considered an unserious person or suspected of privately sympathizing with the wrong side.

Reverence plays a role in any form of education. In the 1990s, humanities departments across the nation were still host to scores of professors who'd come of age before 1960. They'd been nurtured in the traditions of European high culture, having been, in many cases, mentored by Jewish-American refugees from Nazi Germany. When that old guard was replaced, throughout the 1990s and 2000s, by children of the 1960s, the humanities' object of reverence shifted from high culture to political radicalism.

Mr. Bolotin calls for viewing these developments through the frame of hedonism. There is, of course, a hedonistic defense of the liberal arts. Proponents could point out that intellectual pleasure has a special purity and all that they ask is to be left alone, just like those who live for material pleasure. Instead, though, the liberal arts seem to be increasingly subjected to standards of political legitimacy. A classics department had better come up with some sort of social justice reason for its existence if it wants to remain in business. In other contexts, teaching rhetoric/sophistry provided a cross-subsidy for the liberal arts, but that function now seems to have been passed to the social sciences.

To raise the issue of rationalism shifts the focus above the plane of pleasure. Our views of the good determine what we find pleasant. It's no fun to riot for a cause you consider unjust. Mr. Bolotin argues that a crisis of rationalism lies behind our civil discord by motivating so much of the intellectual intimidation going on these days. Bullies do tend to be insecure. Diminished confidence in reason doesn't directly harm economic materialists, because they can always argue that, whatever your conception of the good may be, you're going to need housing, heat, food, and perhaps also even libraries, to pursue it.

But the liberal arts has been unable to establish a basis of respect amidst this ongoing crisis of rationalism. A philosophy student can challenge egalitarianism but only in a naysaying way if he can't offer a more rationally compelling 
alternative. Is the only option left for the liberal arts to recruit bullies of its own? 